\title{
BJSM
}

\section{The effect of rugby shoulder padding on peak impact force attenuation}

D A Harris and I R Spears

Br J Sports Med 2010 44: 200-203

doi: 10.1136/bjsm.2008.047449

Updated information and services can be found at:

http://bjsm.bmj.com/content/44/3/200.full.html

\section{These include:}

References This article cites 17 articles, 8 of which can be accessed free at: http://bjsm.bmj.com/content/44/3/200.full.html\#ref-list-1

Email alerting Receive free email alerts when new articles cite this article. Sign up in the service box at the top right corner of the online article.

Notes

To order reprints of this article go to:

http://bjsm.bmj.com/cgi/reprintform

To subscribe to British Journal of Sports Medicine go to:

http://bjsm.bmj.com/subscriptions 


\title{
The effect of rugby shoulder padding on peak impact force attenuation
}

\author{
D A Harris, I R Spears
}

Teesside Sports Injury Centre, University of Teesside, Middlesbrough, UK

Correspondence to: Deborah A Harris, Teesside Sports Injury Centre, University of Teesside, Victoria Building, Victoria Rd, Middlesbrough, Tees Valley TS1 3BA, UK; d.a.harris@tees.ac.uk

Accepted 6 May 2008

\begin{abstract}
Objective: The introduction of shoulder pads has coincided with a rise in shoulder impact injuries in the game of rugby. In this study, the effect of shoulder pads on impact force attenuation was quantified.
\end{abstract}

Design: Four different commercially available shoulder pads were tested for material properties. Hard and soft objects were dropped from predetermined heights onto a force plate imparting peak impact forces of 500, 1000 and $1500 \mathrm{~N}$. The pads were then placed on the plate and subjected to 10 repeated impacts for each pad and drop height.

Setting: Institutional laboratory setting.

Main outcome measurements: Peak force attenuation, expressed as the percentage reduction of peak force when compared with the no-pad condition, was calculated. Time to peak impact, expressed as the percentage increase of time to peak impact when compared with the no-pad condition, was calculated.

Results: All pads were found to reduce peak impact force and increase time to peak impact. Results varied between $1 \%$ and $70 \%$, depending on the drop height and properties of the impactor. The best performing pad was the thickest, and all pads were best able to attenuate force under hardobject impacts particularly for the lower loads.

Conclusion: Although several limitations exist to laboratory-based studies such as these, the inconsistencies in force attenuation were nonetheless disappointing. The pads appear to "bottom out" under higher-impact loads and therefore offer little protection when the athlete may need it most.

Common shoulder injuries in sporting populations include acromioclavicular joint sprains, glenohumeral dislocation, clavicular fracture and proximal humeral fracture. ${ }^{1}$ Rugby union football is a highcontact sport, and all players are susceptible to a range of injuries. ${ }^{2}$ In an effort to reduce injury rates, several changes to the game have been made by the sport's governing body (International Rugby Board (IRB)). Spear, high tackles and collapsing of the scrum have all been banned. ${ }^{3}$ In response to high shoulder-injury rates, ${ }^{3}$ the governing body has made further changes. Under Law 4, Regulation $12,{ }^{4}$ shoulder padding is now permitted. Specifically, players are permitted to wear shoulder pads, provided the pads are "made of soft and thin materials, which may be incorporated in an undergarment or jersey provided that the pads cover the shoulder and collarbone only. No part of the pads may be thicker than $0.5 \mathrm{~cm}$ when uncompressed. No part of the pads may have a density of more than 45 kilograms per cubic metre". ${ }^{4}$

Marshall $e t a l^{5}$ reported that more than $70 \%$ of players wear shoulder pads because the pads will help to prevent injury, yet many researchers have questioned their effectiveness. For example, it has been suggested that shoulder pads do not protect against fracture, ${ }^{6}$ dislocation, ${ }^{6}$ rotator cuff tears ${ }^{7}$ or glenohumeral instability. ${ }^{7}$ Research has shown that the tackle is the phase of play that accounts for the greatest incidence of injury within rugby union football, ${ }^{89}$ resulting in injury to either the tackler or the player being tackled. ${ }^{10}$ Trewarth and Stokes ${ }^{11}$ reported that peak impact forces on the tackling shoulder ranged from 1 to 1.3 body weight, with forces being localised around the acromioclavicular joint. Most shoulder injuries result in sprains, strains, fractures and dislocations. ${ }^{9}$

The mechanics of fractures, sprains and dislocations is usually attributed to a direct blow to the tip of the shoulder or by falling onto an outstretched hand. Both instances result in impact forces being transmitted into the structures of the shoulder, causing major joint disruption. ${ }^{12}{ }^{13} \mathrm{Few}$, if any, designs of shoulder padding provide sufficient coverage of the lateral shoulder, thereby reducing the likelihood of impact force being dissipated by the padding. Dislocations of the shoulder joint are caused by an extension force being applied to a rotated arm. ${ }^{12}$ No shoulder padding would prevent these mechanics from occurring, as padding is not designed to restrict or limit movement at the glenohumeral joint. At best, it has been suggested that they may protect from lacerations and reduce bruising and haematoma of the soft tissue surrounding the shoulder complex. ${ }^{6}$

Furthermore, these suggestions appear to be borne out by empirical observations. Specifically, despite a $20 \%$ to $36 \%$ increase in the use of shoulder pads between 1999 and 2002, the number of shoulder injuries is on the increase by $12 \%$ to $13 \%$ according to the 2002 Rugby Football Union report. ${ }^{14}$ Having seen an increase in the number of rugby-related shoulder injuries in our sports injury clinic, a decision was taken to investigate the effectiveness of shoulder padding in the reduction of impact.

To date, most of the evidence, with regards to the protective capabilities of the pads, has been anecdotal. As of yet, there have been no published scientific studies attempting to assess the protection offered by shoulder pads. It is generally recognised that an important function of any protective gear is the reduction of impact force exerted on the body. ${ }^{15}$ The aim of this study is to quantify peak force attenuation of commercially available shoulder pads.

\section{METHODOLOGY}

Four commercially available IRB-approved shoulder pads were selected for investigation. These were all constructed using polyvinyl acetate foam but varied 
in thickness and density. Pad 2 (Canterbury Europe, Cheshire, UK) was the thickest $(10 \mathrm{~mm})$, whereas pad 3 (Terminator Clothing, Rushden, UK) was the thinnest ( $4 \mathrm{~mm}$ ). Pads 1 and 4 were the Kooga (Kooga Rugby, Rochdale, UK) and Gilbert (Gilbert, London, UK) and were intermediate in thickness (8 $\mathrm{mm})$.

Each pad was subjected to displacement-controlled loading by indentation (MTS Systems, Eden Prairie, Minneapolis, USA) to quantify the stiffness. The pads were placed on a rigid plate, and a cylindrical stainless steel indentor ( $35 \mathrm{~mm}$ diameter) was attached to the load cell. The indentor was polished smooth to minimise friction and attached to the load cell. The tests were performed at 100 and $50 \mathrm{~mm} / \mathrm{s}$ to isolate any effects of loading rate, and none were found. Maximum force was $250 \mathrm{~N}$.

A mechanism was created that enabled the release of impactors from a predetermined height onto a force platform (model 9281 CA; Kistler Instrument, Winterthur, Switzerland). Spherical objects were chosen as the impactors as these were representative of bony prominences (eg, the greater trochanter) or body parts with which the pads were likely to come into contact. Accordingly, a $2 \mathrm{~kg}$ medicine ball (BBE, York Barbell, Northamptonshire, UK) and a 1-kg hockey ball (J P Lennard, Rugby, UK) were used as the impactors. The magnitude of impact forces during the game of rugby is likely to vary depending on a range of factors, such as the relative momentum of the colliding players or the contraction of the pectoral muscles at the instant of impact. A series of preparatory trials took place, in which the drop height was varied such that these objects imparted peak vertical ground reaction forces of 500 , 1000 and $1500 \mathrm{~N}$ when dropped from the predetermined heights directly onto the force plate. These heights were $0.3,0.7$ and $1.25 \mathrm{~m}$ for the hard impactor and $0.15,0.65$ and $1.6 \mathrm{~m}$ for the soft impactor. The higher loads are lower than, but approaching, the impact conditions reported for collisions in American football (3013 (598) N), ${ }^{16}$ and rugby union scrummaging (3013 (598) N), ${ }^{17}$ whereas the lower loads are considered to represent those encountered during minor collisions. Vertical ground reaction force during the impact stage was sampled by the force platform at $12500 \mathrm{~Hz}$. A reliability study of the mechanism was conducted. Specifically, coefficients of variation over 20 trials of peak impact force and time-to-peak impact force were low ranging between $0.02 \%$ and $5.88 \%$ and between $0.11 \%$ and $7.77 \%$, respectively. Ten trials were then undertaken for each drop height, with and without the pads, with the mean data being reported. Force attenuation was calculated using the following formula:

\section{$\underline{\text { F1-F2 }}$ F1}

where F1 is the no-pad condition and F2 is the pad condition.

Time to peak impact was calculated using the following formula:

\section{$\underline{\text { T1-T2 }}$ T1}

where $\mathrm{T} 1$ is the no-pad condition and T2 is the pad condition. All testing was performed at the University of Teesside's Biomechanics Laboratory.

\section{RESULTS}

The force-displacement data of the four pads $(100 \mathrm{~mm} / \mathrm{s})$ shown in fig $1 \mathrm{~A}$ were converted to stress-strain data in fig $1 \mathrm{~B}$.
The force-deformation plots were dissimilar with pad 3 having the greatest stiffness and pad 1 the least. It can be seen that the pads were similar in terms of material stiffness. The main differences in the force-displacement data were due to thickness.

When tested under low-stiffness impacts and at lower-impact forces $(500 \mathrm{~N})$, peak force attenuations (SD) for pads 1, 2, 3 and 4 were $9.3 \%(0.007 \%), 18.9 \%(0.058 \%), 2.9 \%(0.062 \%)$ and $13.8 \%(0.043 \%)$, respectively (fig 2$)$. Under higher-impact forces $(1500 \mathrm{~N})$, peak force attenuations were $5.63 \%(0.034 \%), 3.7 \%$ $(0.037 \%), 1.9 \%(0.023 \%)$ and $6.0 \%(0.03 \%)$ for pads $1,2,3$ and 4 , respectively. Under high-stiffness impacts, force attenuation was greater. For example, under the low-impact force $(500 \mathrm{~N})$, peak force attenuations were $61.3 \%(0.028 \%), 56.8 \%(0.012 \%)$, $24.2 \%(0.038 \%)$ and $70.2 \%(0.034 \%)$, and under the high-impact force $(1500 \mathrm{~N})$, results were $37.8 \%(0.021 \%), 39.6 \%(0.017 \%)$, $19.8 \%(0.019 \%)$ and $39.3 \%(0.013 \%)$ for pads $1,2,3$ and 4 , respectively.

When tested under low-stiffness impacts and at lower-impact forces $(500 \mathrm{~N})$, time-to-peak impact force for pads 1, 2, 3 and 4 were increased by $23.7 \%(0.0387 \%), 5.91 \%$ (0.0387\%), $6.66 \%$ $(0.0538 \%)$ and $15.83 \%(0.0538 \%)$, respectively, when compared with the unprotected condition ( $11=0.00105$ (0.00028) s) (fig 3). Under higher-impact forces $(1500 \mathrm{~N})$, times to peak impact were $18.76 \%$ (0.14\%), $4.51 \%$ (0.054\%), 9.23\% (0.054\%) and $21.55 \%(0.033 \%)$ for pads $1,2,3$ and 4 , respectively, when compared with the unprotected condition $(0.00095$ (0.000051) s). Under high-stiffness impacts, time to peak impact was slightly less under low-impact forces, although considerably greater under higher-impact forces. For example, under the lowimpact force $(500 \mathrm{~N})$, times to peak impact were $5.055 \%$ (0.393\%), $3.17 \%$ (0.0567\%), $2.457 \% \quad(0.0675 \%)$ and $3.59 \%$ $(0.181 \%)$ when compared with the unprotected condition $(0.0101(0.0008) \mathrm{s})$, and under the high-impact force $(1500 \mathrm{~N})$, results were $67.44 \%(0.198), 54.76 \%(0.125), 43.41 \%(0.066)$ and $66.31 \%(0.404)$ for pads $1,2,3$ and 4 , respectively, when compared with the unprotected condition $(0.0083$ (0.00056) s).

Pad 2 (Canterbury Europe) is the thickest $(10 \mathrm{~mm})$, whereas pad 3 (Terminator Clothing) is the thinnest ( $4 \mathrm{~mm}$ ). Pads 1 and 4 were the Kooga (Kooga Rugby) and Gilbert (Gilbert) and intermediate in terms of thickness $(8 \mathrm{~mm})$.

\section{DISCUSSION}

The study was prompted by questions being raised about the efficacy of shoulder pads in reducing injury rates. ${ }^{67}{ }^{18-20}$ Notably, despite an increased use of pads, the number of shoulder injuries has increased. The aim of this investigation was to quantify the mechanical protection provided by commercially available IRBapproved pads. It is recognised that force attenuation, as is measured in this study, is not the only way the pad can protect the shoulder. For example, the pad could spread and redirect load away from vulnerable anatomical locations (eg, acromioclavicular joint) or, because soft tissues are viscoelastic in their material properties, reduce the rate of loading. Because parameters such as these were not measured, the study is not holistic in quantifying all aspects of shoulder pad protection. Rather, because shoulder injuries are undoubtedly related to internal stress and the magnitude of which will be proportional to the impact force exerted, the quantification of the pad's force-attenuating properties is considered to be a logical first step in this direction.

Currently, the IRB recommends a testing protocol for shoulder pads that involves dropping a $5-\mathrm{kg}$ impactor onto a pad. Accelerometers mounted on the impactor record acceleration and, hence, forces exerted by the pad. In many ways, the 
Figure 1 Force-deformation (left) and stress-strain (right) relationships of the shoulder pads under investigation.

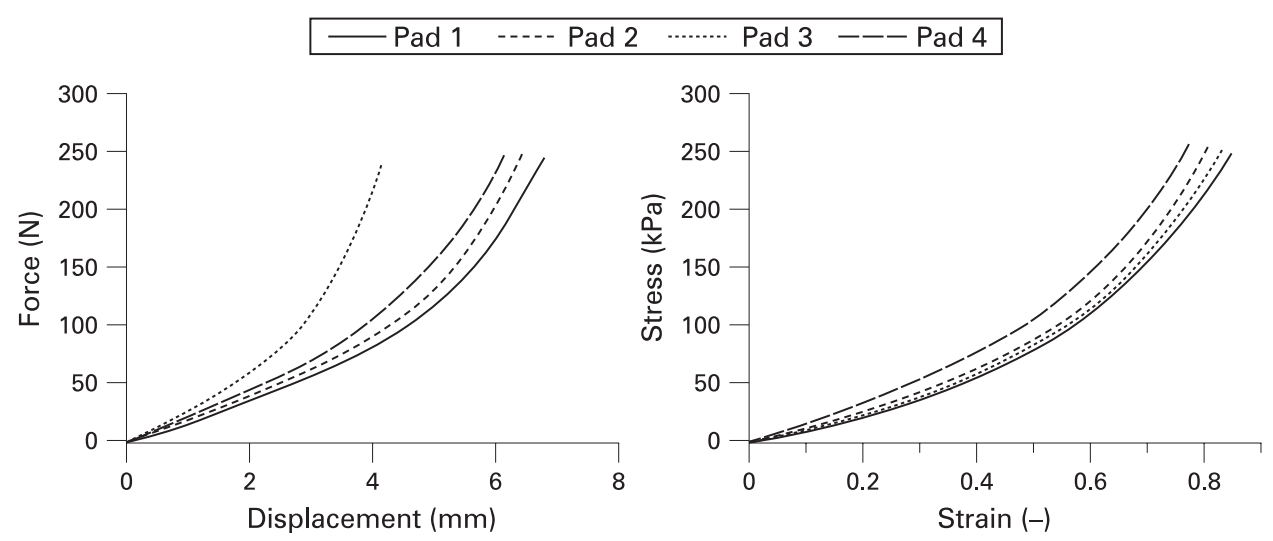

protocol is similar to that used in the present study. However, there were some notable differences. First, the impactors used in the study are spherical, whereas those used in the IRB are flat. These spherical objects will induce a concentration of stress/ strain close to the centre of contact, whereas the flat impactors will exert a more uniform distribution of stress/strain. Second, included in our study was the behaviour of pads under lowstiffness impacts as may occur during tackles involving soft tissue collisions. Third, the pads were tested using different drop heights, thus subjected to a range of impact forces. Thus, taken together, the pads in this study were placed under greater and a wider range of demands than is tested by the IRB protocol. For these reasons, the pads, despite having been passed by the IRB, may fail in some of the tests.

Under low-stiffness impacts, the pads were only able to reduce peak force between $1 \%$ and $20 \%$ and increase time-topeak impact force between $4 \%$ and $23 \%$. Deformation within the low-stiffness impactor prolongs the deceleration phase of the collision and, hence, the impact is self-attenuating. In such cases, the addition of a relatively small layer of cushioning in the form of the pad does not substantially add to this attenuation, and as a result, it is suggested that the attenuation provided by the pads under low-stiffness impacts will do little in terms of injury avoidance. In contrast, under the high-stiffness loads, the pads' attenuating properties were much greater. Peak impact force varied between $20 \%$ and $70 \%$ and time-to-peak impact force varied between $5 \%$ and $75 \%$ and, on first inspection, appear reasonable. The values are similar to those recorded for soccer shin guards $(40 \%-77 \%)^{15}$ and given that shoulder pad designers have considerably lesser freedom in terms of both

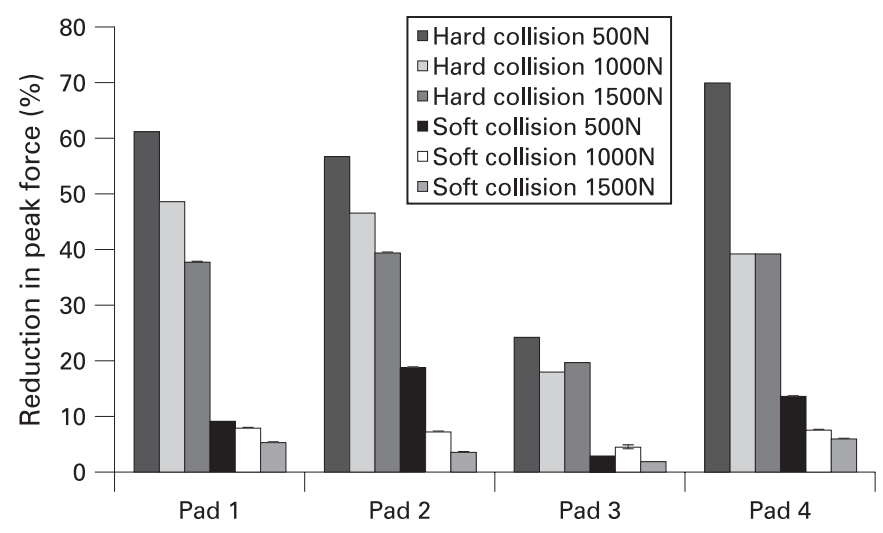

Figure 2 Peak impact force attenuation for hard- and soft-impact collision. governing regulations and playability requirements, the attenuation achieved could be considered an engineering success and may be the critical difference between ligament sprain or rupture. From this perspective, it may be argued that shoulder pads are beneficial to the game. On another positive note, some of the pads were able to provide some force attenuation under all loads (eg, pads 2 and 4). These pads are constructed using stiffer and thicker foam, and this may inform design modifications in the future.

However, on a cautionary note, the attenuating properties vary quite dramatically not just between pads but also under different loads. Whereas the former may be expected given the differences in thickness, the latter may require further explanation. Attenuation, which was generally found to be good for low loads, diminishes quite substantially under higher loads. At low loads (strain $<0.6$ ), the foams are easily deformed and are expected to be able to prolong the deceleration phase of impact by deformation. In contrast, at higher strains (eg, >0.75), the foam cells collapse, and at this stage, the instantaneous stiffness (ie, the local gradient of the stress-strain curve) is high. Consequently, deceleration/forces are high, as the foam may have "bottomed out". If this bottoming out occurs during the game, the impact forces actually transferred into the shoulder joint could be high. This change in attenuation is worrying. Specifically, the good attenuation provided by the pads under the low loads may give the player the false impression of invincibility or reduce the sensory feedback during the early stages of the collision. Harder tackling ${ }^{19}$ would increase impact force but at the same time reduce protection. Such inconsistencies in attenuation, together with psychological factors associated with the padding, may in part explain the increase in

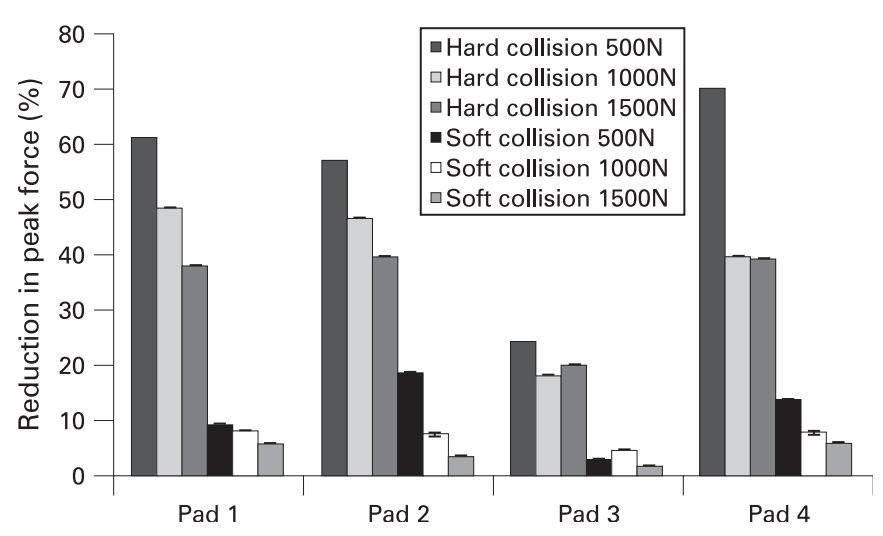

Figure 3 Time-to-peak impact force for hard- and soft-impact collision. 


\section{What is already known on this topic}

Various authors have hypothesised that rugby union shoulder padding is ineffective at preventing injury and have even suggested that its use may create a feeling of invincibility resulting in players tackling poorly and harder than required. However, no empirical research into the actual effects of the padding has been published.

\section{What this study adds}

This study provides evidence that shoulder padding is ineffective in preventing serious injury. It highlights the need to educate players and coaches to the effect that shoulder padding should not be relied on for injury prevention.

injuries associated with the increase in shoulder pad use. ${ }^{19}$ From this perspective, despite undoubtedly attenuating peak force, suggestions that the pads are a danger to the sport may be supported. ${ }^{21}$

To conclude, the pads did consistently reduce peak impact force, but the magnitudes of attenuation are inconsistent. The attenuation is low under low-stiffness impacts. Under the highstiffness impact, the pads are inconsistent; providing much greater attenuation under low loads but lower attenuation under higher loads. Although it may not be possible, given current IRB legislation, to improve on this situation, coaches and players should in the meantime be aware of these limitations.

Competing interests: None.

\section{REFERENCES}

1. Kiner A. Diagnosis and management of grade II acromioclavicular joint separation. Clin Chiropractic 2004; 7:24-30.

2. Marshall SW, Waller AE, Dick RW, et al. An ecologic study of protective equipment and injury in two contact sports. Int J Epidemiol 2002;31:587-92.

3. Garraway $\mathbf{M}$, Macleod D. Epidemiology of rugby football injuries. Lancet 1995:345:1485-7.

4. International Rugby Board. Laws of the game. 1999. www.irb.com/mm/ Document/LawsRegs/0/FULL070110LGLAWSOFTHEGAME2007red_569.pdf (accessed 11 Nov 2007).

5. Marshall SW, Waller AE, Loomis DP, et al. Use of protective equipment in a cohort of rugby players. Med Sci Sports Exerc 2001;33:2131-8.

6. Gerrard DF. The use of padding in rugby union. Sports Med 1998;25:329-32.

7. Bathgate A, Best JP, Craig G, et al. A prospective study of injuries to elite Australian rugby union players. Br J Sports Med 2002;36:265-9.

8. Bird YN, Waller AE, Marshall SW, et al. The New Zealand Rugby injury and performance project: V. Epidemiology of a season of rugby union. Br J Sports Med 1998;32:319-25.

9. Brooks JHM, Fuller CW, Kemp SPT, et al. Epidemiology of injuries in English professional rugby union: part 1 match injuries. Br J Sports Med 2005;39:757-66.

10. Wilson BD, Quarrie KL, Milburn PD, et al. The nature and circumstances of tackle injuries in ruby union. J Sci Med Sport 1999;2:153-62.

11. Trewarth G, Stokes K. Impact forces during rugby tackles [abstract]. Proceedings of the International Conference on the Science and Practice of Rugby; 5-7 Nov 2003, Brisbane, Australia, 25.

12. Amin AK, Robinson CM. Fractures and dislocations of the shoulder girdle. Surgery 2006:24:415-20.

13. Nowak J, Mallmin H, Larsson S. The aetiology and epidemiology of clavicular fracture. A prospective study during a two-year period in Uppsala, Sweden. Injury 1999:31:353-8

14. Rugby Football Union. Governance committee players' safety. A statement of serious and very serious injuries reported to the RFU by clubs and schools for the five seasons 1997-2002. Twickenham, UK: Rugby Football Union, 2002:1-8.

15. Bir CA, Cassatta SJ, Janda D. An analysis and comparison of soccer shin guards Clin J Sports Med 1995;5:95-9.

16. Gatt CJ Jr, Hosea TM, Palumbo RC, et al. Impact loading of the lumbar spine during football blocking. Am J Sports Med 1997;25:317-21.

17. Milburn PD. The biomechanics of rugby union scrummaging: implications for technique and injury. Sports Med 1993;16:168-79.

18. Hood M. Preparation, performance and patch up - a guide to fitness training and injury prevention. Auckland, NZ: Heinemann, 1980:25.

19. Garraway WM, Lee AJ, Hutton SJ, et al. Impact of professionalism on injuries in rugby union. Br J Sports Med 2000;34:348-51.

20. Garraway WM, Lee AJ, Macleod DAD, et al. Factors influencing tackle injuries in rugby union football. Br J Sports Med 1999;33:37-41.

21. Finch CF, Mclntosh AS, McCrory P. What do under 15 year old schoolboy rugby union players think about protective headgear? Br J Sports Med 2001;35:89-94. 